\title{
Ontology Analysis of Teachers' Teaching Sensitivity
}

\author{
Han Xing* \\ Department of Education, Southwest University, Chongqing 400715, China.
}

\begin{abstract}
At present, whether in the field of academic research or in the field of practice, a consensus has gradually formed, that is, how teachers achieve their own professional development, in addition to relying on some external training or institutional forces, the more fundamental is to rely on teachers' inner awakening. Teaching sensitivity is one of the important aspects, which has an important impact on education, and enables teachers to touch the educational activities themselves and obtain the wisdom of education. This paper discusses the ontological structure of teachers' teaching sensitivity, constructs the manifestation and characteristics of teachers' teaching sensitivity, so as to expand the research field of teachers' practical knowledge.
\end{abstract}

Keywords: Teaching Sensitivity; Manifestation; Characteristics

\section{Concept}

"Sensitivity" originated from a special term in the field of biology, which refers to "the characteristics of an organism or a part of it that are easy to feel for certain factors ${ }^{[1]}$." Teaching sensitivity is a special directional ability of teachers in the teaching process, and it is also a psychological ability of teachers engaged in teaching work. As for the essence of teaching sensitivity, it has the dual attributes of "thinking consciousness" and "professional quality". Therefore, in the professional development of teachers, the generation of teaching sensitivity inevitably comes from educational practice. Through practice, teaching experience is generated, and then "teaching sensitivity" is extracted from the reflection of teaching experience, so that it becomes a part of teachers' professional quality. The essence of teaching sensitivity is the practical experience summed up by teachers in the longterm teaching process. Therefore, the connotation of "teaching sensitivity" is that teachers have a hazy prediction of various teaching phenomena, concepts and behaviors, and have a keen insight into the situational significance of teaching and the students' reactions and related developmental relations aroused by it.

\section{Form of expression}

\subsection{Keen awareness of teaching situation}

Teaching sensitivity is based on Teachers' situational knowledge and characterized by their teaching tact. Teachers are practical workers in the educational situation. The educational situation is complex and uncertain. Teachers show their wit and wisdom in dealing with the educational situation, which contains teachers' situational knowledge ${ }^{[2]}$. Teachers' keen awareness of teaching situation is the ability of teachers to use teaching tact to perceive and grasp every detail in the classroom in different time and space, so that teachers can make accurate and reasonable judgments on the observed things, and then make reasonable predictions for the future. It is the key link for teachers to know things, judge things, and create things. In the teaching situation, it is precisely because of teachers' keen awareness and grasp of all kinds of key teaching details that teachers can make cognitive judgments on the observed things and carry out further actions, so as to organically link the external appearance of things with their own internal educational wisdom.

\subsection{Perception of students' emotion}

Teachers' accurate perception of students' emotions can help teachers build up their understanding of teaching, expand their sensitivity range, and produce the sensitivity consciousness of teaching, which is the soil for the germination of educational wisdom. Emotion is an attempt by an individual to establish, maintain, change and terminate the relationship between human and environment under meaningful circumstances ${ }^{[3]}$. For students, the expression of emotion is not only the reflection of objective things, but also has internal "display rules" ${ }^{[4]}$, that is, students' emotion control reflects their internal psychological needs to a certain extent. Therefore, teachers' perception of students' emotions is embodied in teachers' perception of students' current emotions and satisfaction of their potential psychological needs. "This kind of perception is not born by teachers, but acquired educational sensitivity"[5], which is an active perception ability.

\subsection{Wisdom in dealing with educational phenomena}

Educational phenomenon is the external manifestation of education, which exists in the events and processes of educational

Copyright (C) 2020 Han Xing

doi: 10.18282/1-e.v9i4.1732

This is an open-access article distributed under the terms of the Creative Commons Attribution Non-Commercial License (http://creativecommons.org/licenses/by-nc/4.0/), which permits unrestricted non-commercial use, distribution, and reproduction in any medium, provided the original work is properly cited. 
activities. It includes educational facts of various forms, types and modes. In the face of explicit educational phenomenon, teachers' processing wisdom is an important manifestation of teachers' teaching sensitivity. The main manifestation of teaching sensitivity is teachers' wisdom in dealing with teaching phenomena. For teachers, "judgment is the result of some conscious thinking, representing a special way to act or the intention to produce an expected result"[6]. Teaching sensitivity is a dynamic process in which teachers judge and deal with the teaching situation, that is, between decision-making and implementation, teachers make their own judgment on the teaching phenomenon by virtue of "the priority of teaching objectives, the on-the-spot performance of students' learning, the change of teaching atmosphere and so on"[7], so as to properly deal with the wisdom of educational phenomenon.

\subsection{Reflection on teaching action}

Teaching action is the timely response of teachers according to their own experience, ideas and intuition. Teachers' Reflection on teaching action is the generation part of teaching sensitivity. In order to improve the teaching action, teachers can find their own advantages and disadvantages in the teaching process by reflecting on the results, experience and concepts involved in their own teaching action. The advantages will be transformed into teachers' personal experience and become the "case bank" stored in their minds, which will provide the basis for solving similar problems in the future. It can be seen that reflection is an important generation channel of teachers' teaching sensitivity. It is because of teachers' reflection on teaching actions that teachers can acquire and constantly improve their teaching sensitivity, come into contact with the "truth" of education, and give birth to the "wisdom" of education, so that they will no longer be the "teaching machine" that can only follow the book, but become the "thinker" of education.

\section{Characteristics}

\subsection{Practicality}

Teaching sensitivity is based on human cognitive activities, and it has no specific form of expression. Only by taking practice as its main carrier, can it show its own essential state through teachers' practical activities. It can be said that teaching sensitivity, as a teacher's professional ability generated in the long-term teaching action, fundamentally comes from practice. Only in practice can teaching sensitivity be understood, and only in practice can teaching sensitivity be developed. They are interdependent, and the teaching sensitivity separated from practice is only an abstract and unintentional one. Therefore, the teaching sensitivity must have the distinct characteristics of practicality. This shows that teaching sensitivity cannot exist independently without specific practice, so we regard practicality as the most essential feature of teaching sensitivity.

\subsection{Individuality}

For each teacher, they come from different families, receive different education and have different growth experiences, so they have different personal experiences, experiences and personality characteristics. It is these different "histories" that constitute each person's "habits". Affected and restricted by the "habits" factors, each teacher will have a different understanding of education itself. They also have completely different understandings of educational practice. Reflected in the teaching sensitivity, based on the interpretation of individual understanding, there must be great differences in the level, stage, degree and tendency of teachers' teaching sensitivity. Teaching sensitivity will be restricted by personal past experience and ability and qualification to varying degrees, so it must have distinct "individuality" characteristics.

\subsection{Situational}

Situation is an indispensable basic factor in the formation of teaching sensitivity. For teachers, any teaching practice must take place in specific situations. Teaching sensitivity is the product of interaction between teachers and specific situations. On the one hand, only when teachers are in the real and specific "situation", can they stimulate the relevant knowledge and experience in their minds, use their own teaching sensitivity, and make specific responses to the stimulation of the situation. On the other hand, teaching sensitivity is born in the specific situation. Only when teachers face the specific teaching situation, they can obtain teaching experience and improve their teaching sensitivity. Once they are separated from the specific situation, the existence of teaching sensitivity is out of the question.

\subsection{Silence}

Polanyi put forward the concept of tacit knowledge in 1958. He thought: "there are two kinds of human knowledge. One kind of knowledge is expressed in written words, charts and numerical formulas. Knowledge that is not expressed, like the knowledge we have in the action of something, is another kind of knowledge ${ }^{[8]}$." Silence is an existing form of teaching sensitivity. Teaching sensitivity is often reflected as a kind of consciousness based on intuition, which can only be expressed through the ability of teachers in the process of education and teaching, and can be displayed in the sense of "narrative". Therefore, teaching sensitivity is unspeakable in the level of expression, and has the meaning of typical psychological characteristics. In the acquisition level of teaching sensitivity, teaching sensitivity is difficult to systematize and theorize, which requires teachers to experience and comprehend in the long-term teaching practice, so it has the characteristics of silence in the acquisition level.

\section{Reference}

[1]Ci Hai [Z]. Shanghai: Shanghai Dictionary Publishing House, 1980:1471.

[2]Zhong Qiquan. Research on Teachers' practical knowledge [M]. Shanghai: East China Normal University Press, $2008: 124$.

[3]Campos,J. The New Functionalism In Emotion[J], SRCD Newsletter, 1994:285.

[4]Saarni, C. Socialization of emotion[M],New York: Guilford Press, 1993: 417-434. 


\title{
The Application Strategy of Chinese and Western Traditional Painting Color to Student Education
}

\author{
Haijun Yan * \\ Geely University of China, Dazhou, Sichuan 610000, China.
}

\begin{abstract}
Chromatology in the field of design status is increasingly prominent, through the training of painting chromatology to improve the students' design color expression, creativity to meet the needs of modern development, has become the focus of the discussion. In teaching, chromatology should not only stay in a single surface color, but also be combined with the Chinese and Western cultural painting colors. The structure and concept of color in Chinese and Western art should be systematically studied, and specialized subjects should be adopted to continue the study of subjective color training, so as to try to express one's feelings to the objective world through painting color and create the expression form of traditional painting color in contemporary Chinese and Western art. Combined with the professional training of design ketone, the subjective color and high pressure color aesthetic taste will be gradually formed, and the cultural connotation of design will be enhanced.
\end{abstract}

Keywords: Chinese and Western Traditional Painting; Painting Color; Color Teaching Strategy Art

\section{View of Chinese and western colors}

Through drawing lessons from the Chinese and western color view, seeking rich color language expression way, in a higher artistic level determines the pace of Chinese art, helps us to better grasp the power of modern art innovation and creative source. Chinese and western painting art has similarity.

\subsection{Chinese traditional painting colors}

Traditional Chinese painting pays attention to "according to the type of color", but its color is not the pursuit of the object color sense of reality, neither environmental color, nor completely inherent color, with the painter's great subjective creativity, to express a certain feeling. Such as murals, folk New Year pictures, heavy color scroll paintings, commonly used pure, bright colors cause brilliant, bright tone. The color stimulation of Chinese plastic arts is much calmer.In the attitude towards color, the cultural differences between China and the West doomed the wisdom of color. In the beginning, Chinese art paid much attention to colors. For example, vermilion and cyan were commonly used in painting, so they became red and blue. Reflect people's deep impression and recognition of painting color language. Roughly speaking: the color of Chinese painting before the Tang and Song dynasties is a color, mainly reflected in the fresco, silk painting, lacquer decoration, green landscape painting. For example, green landscape paintings are created to cater to the life situation of the royal family and their relatives. They are resplendent in color and have a strong decorative effect. The paintings of Wang Ximeng, a writer in the Northern Song Dynasty, were still bright and beautiful after a long time. The author organized and allocated colors in the paintings, paying attention to the contrast of the thickness of the colors used. By contrast, the mountain is thick painted green, and the back of the meeting is dyed with powder to increase the sense of thickness. At the same time, light daub is used on the silk to express the water surface, leaving a subtle and elegant temperament.

\subsection{Western painting colors}

Westerners are extremely good at using and presenting colors. The origin of Western art in ancient Greece has been mistaken for a pure world without coloring for a long time. Because many of the architectural relics and sculptures that remain are in the original colors of the materials. But the archaeology of the 20th century shows people the true colors of ancient Greek art. In the researchers' restoration of ancient Greek buildings, bright colors can be seen almost everywhere.

Christian art also attaches great importance to the use of color. Mosaic is an important means of art, decoration in the Byzantine

Copyright (C) 2020 Haijun Yan

doi: 10.18282/l-e.v9i4.1733

This is an open-access article distributed under the terms of the Creative Commons Attribution Non-Commercial License (http://creativecommons.org/licenses/by-nc/4.0/), which permits unrestricted non-commercial use, distribution, and reproduction in any medium, provided the original work is properly cited.

[5]Sun Binghai. Comparison of the consistency between different types of students' emotional self perception and teachers' judgment [J]. China special education. 2010, (02): 11-12.

[6]Jiang Shanye. Concise International Encyclopedia of education curriculum [M]. Beijing: Educational Science Press, $1991: 108$. [7]Shi Zhaoli. Students' classroom power, teacher-student relationship and classroom intergenerational resource allocation [J]. Educational theory and practice. 2018, (11): 22-23.

[8] Shi Zhongying. Knowledge transformation and educational reform [M]. Beijing: Educational Science Press, $2001: 233$. 